\title{
Fungal Pericarditis
}

National Cancer Institute

\section{Source}

National Cancer Institute. Fungal Pericarditis. NCI Thesaurus. Code C128406.

Pericarditis that is caused by an infection with a fungal agent. 